\title{
A comparative study on the pharmacovigilance scoring of causality assessment grading and staging of topical pharmacotherapy of ofloxacin $0.3 \%$ ophthalmic solution in bacterial conjunctivitis and ofloxacin $0.3 \%$ otic solution in otitis externa
}

\begin{abstract}
Moumita Hazra ${ }^{1-4 *}$
${ }^{1}$ Department of Pharmacology, Mamata Medical College and Hospitals, Khammam, Telangana, India; ${ }^{2}$ Department of Pharmacology, Rama Medical College Hospital and Research Centre, Kanpur, Uttar Pradesh, India; ${ }^{3}$ Medical Director, Medical Superintendent, Laboratory Director, Medical Academics and Research Director, Consultant Clinical Pharmacological Physician, Consultant Clinical Pathologist, Consultant Drug Quality and Safety Physician, PharmacoHaemo-Materio-Vigilance Specialist, Dr. Moumita Hazra's Polyclinic and Diagnostic Centre, Dr. Moumita Hazra's Academic Centre, Dr. Moumita Hazra's Educational Centre, Hazra Nursing Home, Howrah, Kolkata, West Bengal, India, World; ${ }^{4}$ Former Assistant Medical Director, GIOSTAR IRM Institutes, Hospitals and Laboratories, New Delhi, India, USA, World
\end{abstract}

Received: 05 December 2021

Revised: 03 January 2022

Accepted: 04 January 2022

*Correspondence:

Dr. Moumita Hazra,

Email: drmoumitahazra.198017thjune@gmail.com

Copyright: () the author(s), publisher and licensee Medip Academy. This is an open-access article distributed under the terms of the Creative Commons Attribution Non-Commercial License, which permits unrestricted non-commercial use, distribution, and reproduction in any medium, provided the original work is properly cited.

\begin{abstract}
Background: Topical pharmacotherapeutic modalities would minimalize systemic adverse effects. Ofloxacin, the bactericidal racemic mixture, has inhibitory effects on DNA gyrase, DNA topoisomerase IV and IL-1 $\alpha$, IL-6, and IL-8. This was a comparative study for pharmacovigilance scoring of causality assessment grading and staging of topical ofloxacin pharmacotherapy in bacterial conjunctivitis and otitis externa.

Methods: Group A=50 bacterial conjunctivitis patients were prescribed topical ophthalmic $0.3 \%$ ofloxacin, 2 drops in each eye after every 3 hours for 2 days, and 2 drops in each eye after every 6 hours for next 5 days; and group B=50 otitis externa patients were prescribed topical otic $0.3 \%$ ofloxacin, 3 drops in each ear after every 6 hours for first 2 days, and 5 drops in each ear after every 12 hours for next 5 days. Comparative adverse drug reactions occurrence, like transient ocular burning or discomfort, ocular irritation, redness, stinging, pruritis, photophobia, ocular watering and dryness in group A, and pruritis, headache, dizziness, mild ear pain, rashes, and hypersensitivity reactions in group B, were analysed with adverse event case report forms, on days $0,3,5,7,10,15,30$, and on follow-ups, with causality assessment scores, from adverse drug reactions grading and staging.

Results: The occurrence of adverse effects were statistically non-significant, in both groups, with causality assessment scoring for group A: -11 , none on average=Unlikely causality, and group B: -11 , none on average= Unlikely causality. Conclusions: Topical ofloxacin therapy in group A and group B patients, were safe and tolerable; with nil causality of association of adverse drug reactions.
\end{abstract}

Keywords: Pharmacovigilance, Pharmacovigilance causality assessment grading and staging scores, Fluoroquinolones, Ofloxacin, Bacterial conjunctivitis, Otitis externa, Topical pharmacotherapy 


\section{INTRODUCTION}

Topical pharmaco-prophylactic and pharmacotherapeutic modalities would always remain the safest, as these would benefit the patients, by minimalizing the systemic adverse effects. The majority of new fluoroquinolones have two ionizable functions: the 3-carboxyl group and a protonizable site at position 7 , such as a 7-piperazinyl heterocycle. Ofloxacin, the racemic mixture, has its inhibitory effect on DNA gyrase, DNA topoisomerase IV and pro-inflammatory cytokines interleukins: IL-1 $\alpha$, IL-6, IL-8 and tumour necrosis factor $\alpha$, along with their superinducing effect on IL-2. $0.3 \%$ ofloxacin ophthalmic solution and $0.3 \%$ ofloxacin otic solution are indicated for the treatment of conjunctivitis and otitis, when caused by susceptible strains of the Staphylococcus aureus, Staphylococcus epidermidis, Streptococcus pneumoniae, Haemophilus influenzae, Pseudomonas aeruginosa, Proteus mirabilis, and Moraxella catarrhalis. The efficacy of ofloxacin is attributed to its good penetration into the tissues of the eye, ear, nose and throat. Topical $0.3 \%$ ofloxacin otic solution and ophthalmic solution were demonstrated to be efficacious, without ototoxic effects and ophthalmic toxicity in pre-clinical and clinical investigations and in the treatment of bacterial conjunctivitis, the otitis externa as well as the otitis media. ${ }^{1-11}$

\section{Objectives}

The objective of this comparative study was the pharmacovigilance scoring of causality assessment grading and staging of topical pharmacotherapy of ofloxacin $0.3 \%$ ophthalmic solution in bacterial conjunctivitis and ofloxacin $0.3 \%$ otic solution in otitis externa.

\section{METHODS}

\section{Study type}

It was a multi-centre, prospective, comparative, openlabelled study.

\section{Study place}

The research study and the compilation of the study literature was done in the departments of pharmacology, clinical pharmacology, rational pharmacotherapeutics, pharmacoepidemiology, pharmacovigilance, pathology, clinical pathology, internal medicine, ophthalmology, otorhinolaryngology, respiratory and chest medicine, and clinical research, in the global multi-centre tertiary care hospitals, like, Dr. Moumita Hazra's polyclinic and diagnostic centre, Hazra nursing home, Mamata medical college and hospitals, Rama medical college hospital and research centre and Rama university, Shri Ramkrishna institute of medical sciences and Sanaka hospitals, and J. J. M. medical college and hospitals.

\section{Study period}

The study period, comprising of the periods for the research study and the compilation of the study literature, was 9 months, June, 2015; from December, 2017 to January, 2018; and from July, 2021 to January, 2022.

\section{Selection criteria of the patients}

The inclusion criteria of the patients were the patients of any gender, patients within 21 and 43 years, patients suffering from bacterial conjunctivitis and otitis externa, with a baseline antibiotic susceptibility testing result confirming sensitivity to ofloxacin, co-operative and conscious patients, patients willing to undergo all pre and post-treatment investigations and willing to complete the entire course of treatment, patients who have given consent and are willing to go for a follow-up, and patients not taking any previously started or any concomitant medication.

\section{Study population}

The study population consisted of 50 bacterial conjunctivitis patients and 50 otitis externa patients.

The exclusion criteria of the patients were the cooperative or unconscious patients, patients below 21 and above 43 years, patients presenting with any disease other than bacterial conjunctivitis and otitis externa, patients with a history of hypersensitivity to any of the study drugs, patients with high risk diseases, cardiac, renal or any other associated complications or co-morbidities, any chronic disease intervening with the study data, immunocompromised patients, patients suffering from gastrointestinal diseases like peptic ulcer, regional enteritis and ulcerative colitis, pregnant or lactating women (women of child bearing potential are required to have a negative urine pregnancy test result and to agree to use an effective form of contraception for the duration of study), children or very old patients, other associated medical illness or disorders having impact on study results, and female patients using hormonal contraceptives.

\section{Study procedure}

In this study, group $A=50$ patients suffering from bacterial conjunctivitis and group $\mathrm{B}=50$ patients suffering from otitis externa, were selected. Group A patients were prescribed the topical instillation of ofloxacin $0.3 \%$ ophthalmic solution, 2 drops in each eye at every 3 hours interval for the first 2 days, and then 2 drops in each eye at every 6 hours interval for the next 5 days. Group B patients were prescribed the topical instillation of ofloxacin $0.3 \%$ otic solution 3 drops in each ear at every 6 hours interval for the first 2 days, and then 5 drops in each ear at every 12 hours interval for the next 5 days.

From the 50 bacterial conjunctivitis patients and 50 otitis externa patients, thorough patients' history with complete 
examination details, before and after the administration of the study drugs therapy were obtained with the study proforma, thoroughly analysed and the following details were recorded: the patients' participation assessment and adherence to treatment, including patients who completed the study thoroughly, drop-out patients due to adverse effects, lost to follow-up patients, and patients who withdrew voluntarily; the demographic characteristics, including age, gender, race, duration of symptoms of bacterial conjunctivitis and otitis externa, severity of the symptoms, present controller medications, the patients' present and past history, ophthalmological and otorhinolaryngological history including infection and immunological history, history of any previous injury, abnormality, or surgery, history of usage of contact lens, spectacles or any other ophthalmological or otorhinolaryngological technology supplements or attachments, past investigations and treatment history, drug susceptibility testing results, history of comorbidities and concomitant medications, surgical history, family history, personal history, socio-economic history, reproductive history, and the symptomatic effect of ophthalmological or otorhinolaryngological treatment. Details of complete general physical examination, and systemic examination, including special senses neurological examinations like, ophthalmological, and oto-rhino-laryngo-tracheal examinations, as well as cardio-respiratory examinations and were recorded.

The pharmacovigilance safety assessment was done by the monitoring of adverse drug reactions, like transient ocular burning or discomfort, ocular irritation, redness, stinging, pruritis, photophobia, ocular watering, and dryness, in group A patients (ofloxacin $0.3 \%$ ophthalmic solution therapy), and adverse drug reactions, like pruritis, headache, dizziness, mild ear pain, rashes, and hypersensitivity reactions, in group B patients (ofloxacin $0.3 \%$ otic solution therapy); and recording the findings in the adverse event case report forms, on days $0,3,5,7,10$, 15,30 , and on further follow-ups.

The safety assessment for group A and group B was also done by recording and thoroughly analysing the details of the suspected drug causing adverse effects, drug dose, route of administration, drug frequency, drug starting date, drug stopping date, expiry date of the drug, batch no. / lot no. of the drug, drug manufacturer's name, brand/ generic name of the drug, indications for the usage of the suspected drug, any concomitant medicines, description of adverse reaction : clinical and pharmacological, supporting laboratory investigation results, treatment given for the adverse drug reaction, any specific antagonistic drug given to treat the adverse reactions as well as the clinical outcomes.

The adverse drug reactions listed by MedDRA system organ class and preferred term were taken into consideration, along with emphasis on the adverse reactions, within each system organ class, under frequency categories of very common $(\geq 1 / 10)$, common $(\geq 1 / 100$ to
$<1 / 10)$, uncommon $(\geq 1 / 1000$ to $<1 / 100)$, rare $(\geq 1 / 10,000$ to $<1 / 1,000)$, very rare $(<1 / 10,000)$, and not known (cannot be estimated from the available data). The analysis of different attributes of patient compliance was also performed.

The comparative pharmacotherapeutic occurrence of adverse effects, due to topical ofloxacin $0.3 \%$ ophthalmic solution therapy and topical ofloxacin $0.3 \%$ otic solution therapy was thoroughly analysed, with adequate consideration of causality assessment grading and staging. Finally, in accordance with the pharmacovigilance causality assessment grading and staging scores (Table 5), the causality assessment score was deduced from the grading and staging of the adverse drug reactions, sequentially [Sources of excerpts: Naranjo algorithmadverse drug reactions probability scale shown in the Table 1 and world health organisation (WHO)-Uppsala monitoring centre causality categories shown in the Table 2 modified and adapted, in the compilation of causality assessment score estimation methodology, by grading and staging of the causality of adverse drug reactions]. ${ }^{12,13}$ The causality assessment attributes analysed and graded were (i) history of hypersensitivity to the same drug administered; (ii) history of hypersensitivity to the same generic category of drug administered; (iii) history of adverse drug reaction-like symptoms previously; (iv) occurrence of adverse drug reaction after suspected drug administration; (v) improvement of adverse drug effects after discontinuation of drug, modification of drug dose, alternate drug administration, or specific antagonist administration; (vi) appearance of adverse drug effects after re-continuation of drug, reversal to previous drug dose on patient stabilization, reversal to previous drug administration, or discontinuation of antagonist administration; (vii) alternative co-existing sources, like disease or medications, causing adverse drug effect-like reaction; (viii) false adverse drug effect mimicking reactions; (ix) appearance of adverse drug effect with a placebo; ( $\mathrm{x}$ ) detection of suspected drug in body fluids in toxic concentrations; (xi) severity of adverse drug reactions with increase or decrease of drug dose and (xii) occurrence of adverse drug reactions with the suspected drug in a time-variant or place-variant manner, with the grading of: $y e s=+1$, no $=-1$, and uncertain $=0$. The causality assessment grades were subsequently staged into none, mild, moderate or severe stages. Then, the causality assessment scores were derived from the recorded grading and staging, as follows: a) $\geq 9$, severe on average $=$ Definite causality of adverse drug reaction, b) 5-8, moderate-severe on average $=$ Probable causality of adverse drug reaction, $c$ ) 1-4, mild-moderate on average $=$ Possible causality of adverse drug reaction, d) $\leq 0$, mild or none on average $=$ Doubtful/ Unlikely causality of adverse drug reaction, e) $\leq 0->0$ variable, variable on average $=$ Conditional $/$ unclassified causality of adverse drug reaction and $\mathrm{f}) \geq 0$ variable, variable on average $=\mathrm{Un}$ assessable/unclassifiable causality of adverse drug reaction. 
Table 1: Naranjo algorithm-adverse drug reaction probability scale. ${ }^{12}$

\begin{tabular}{|c|c|c|}
\hline Scores & $\begin{array}{l}\text { Adverse drug } \\
\text { reaction categories }\end{array}$ & Interpretation of scores \\
\hline $\begin{array}{l}\text { Total score: } \\
\geq 9\end{array}$ & Definite & $\begin{array}{l}\text { The reaction (1) followed a reasonable temporal sequence after a drug or in } \\
\text { which a toxic drug level had been established in body fluids or tissues, }(2) \\
\text { followed a recognized response to the suspected drug, and ( } 3 \text { ) was confirmed } \\
\text { by improvement on withdrawing the drug and reappeared on re-exposure. }\end{array}$ \\
\hline $\begin{array}{l}\text { Total score: } \\
5 \text { to } 8\end{array}$ & Probable & $\begin{array}{l}\text { The reaction (1) followed a reasonable temporal sequence after a drug, ( } 2 \text { ) } \\
\text { followed a recognized response to the suspected drug, ( } 3 \text { ) was confirmed by } \\
\text { withdrawal but not by exposure to the drug, and (4) could not be reasonably } \\
\text { explained by the known characteristics of the patient's clinical state. }\end{array}$ \\
\hline $\begin{array}{l}\text { Total score: } \\
1 \text { to } 4\end{array}$ & Possible & $\begin{array}{l}\text { The reaction (1) followed a temporal sequence after a drug, (2) possibly } \\
\text { followed a recognized pattern to the suspected drug, and ( } 3 \text { ) could be } \\
\text { explained by characteristics of the patient's disease. }\end{array}$ \\
\hline Total score: $\leq \mathbf{0}$ & Doubtful & The reaction was likely related to factors other than a drug. \\
\hline
\end{tabular}

Table 2: World health organisation-Uppsala monitoring centre causality categories. ${ }^{13}$

\begin{tabular}{|c|c|}
\hline Causality term & Assessment criteria \\
\hline Certain & $\begin{array}{l}\text { Event or laboratory test abnormality, with plausible time relationship to drug } \\
\text { intake, } \\
\text { Cannot be explained by disease or other drugs } \\
\text { Response to withdrawal plausible (pharmacologically, pathologically), } \\
\text { Event definitive pharmacologically or phenomenologically (i.e., an objective and } \\
\text { specific medical disorder or a recognised pharmacological phenomenon), } \\
\text { Rechallenge satisfactory, if necessary. }\end{array}$ \\
\hline Probable/ likely & $\begin{array}{l}\text { Event or laboratory test abnormality, with reasonable time relationship to drug } \\
\text { intake, } \\
\text { Unlikely to be attributed to disease or other drugs, } \\
\text { Response to withdrawal clinically reasonable, } \\
\text { Rechallenge not required. }\end{array}$ \\
\hline Possible & $\begin{array}{l}\text { Event or laboratory test abnormality, with reasonable time relationship to drug } \\
\text { intake, } \\
\text { Could also be explained by disease or other drugs, } \\
\text { Information on drug withdrawal may be lacking or unclear. }\end{array}$ \\
\hline Unlikely & $\begin{array}{l}\text { Event or laboratory test abnormality, with a time to drug intake that makes a } \\
\text { relationship improbable (but not impossible), } \\
\text { Disease or other drugs provide plausible explanations }\end{array}$ \\
\hline Conditional/ unclassified & $\begin{array}{l}\text { Event or laboratory test abnormality, } \\
\text { More data for proper assessment needed, or } \\
\text { Additional data under examination. }\end{array}$ \\
\hline Un assessable/ unclassifiable & $\begin{array}{l}\text { Report suggesting an adverse reaction, } \\
\text { Cannot be judged because information is insufficient or contradictory, } \\
\text { Data cannot be supplemented or verified }\end{array}$ \\
\hline
\end{tabular}

\section{Ethical approval}

At first, the institutional ethics committee clearance and approval was taken. The study was conducted in accordance with the ethical principles of declaration of Helsinki and good clinical practices contained within the international council for harmonization of technical requirements for pharmaceuticals for human use (ICH-E6 and the ICH-E17), and in the compliance with the global regulatory requirements. The patients who were included in the study were assured confidentiality, and an informed consent was obtained from each patient.

\section{Statistical analysis}

The statistical analyses were test of significance with $p$ values, with subsequent tabular representations.

\section{RESULTS}

All the patients completed the treatment thoroughly. There were no dropout patients due to adverse effects, no patients were lost to follow-up and no patients voluntarily withdrew. The patients' adherence to anti-tubercular treatment was very high. The demographic characteristics of the group A and group B, were comparable. Adverse 
effects were negligible in either group. Thus safety assessment showed that both in group A (Table 3) and group B (Table 4) patients, the occurrence of adverse effects was statistically non-significant. Tolerability was good for both ofloxacin $0.3 \%$ ophthalmic solution and ofloxacin $0.3 \%$ otic solution, in bacterial conjunctivitis and otitis externa patients.

For ofloxacin $0.3 \%$ ophthalmic therapy, the causality grading was 'yes' $=+1$ for 1 attribute: occurrence of adverse drug reaction after the suspected drug administration, and 'no'=-1 for other attributes, with causality staging of 'mild' for 1 attribute, and 'none', for other causality assessment attributes, because there was occurrence of transient ocular discomfort in only 1 patient, the first day, which reduced within 24 hours, on drug adaptation with time. For ofloxacin $0.3 \%$ otic therapy, the causality grading was 'yes' $=+1$ for 1 attribute: occurrence of adverse drug reaction after the suspected drug administration, and 'no' $=-1$ for other attributes, with causality staging of 'mild' for 1 attribute, and none, for other causality assessment attributes, because there was occurrence of mild pruritis in only 1 patient, the first day, which also reduced within 24 hours, on drug adaptation with time. Therefore, in accordance with the pharmacovigilance causality assessment grading and staging scores (Table 5), the causality assessment scoring for group A on ofloxacin $0.3 \%$ ophthalmic therapy was11 , none on average $=$ Unlikely causality of adverse drug reaction, because the occurrence of adverse effects in group A was statistically non-significant; and the causality assessment scoring for group B on ofloxacin $0.3 \%$ otic therapy was-11, none on average=Unlikely causality of adverse drug reaction, because the occurrence of adverse effects in group B was statistically non-significant.

Table 3: Group A: occurrence of adverse effects with topical $0.3 \%$ ofloxacin ophthalmic solution therapy.

\begin{tabular}{|lll|}
\hline $\begin{array}{l}\text { Adverse effects of } \\
\text { 0.3\% ofloxacin } \\
\text { ophthalmic solution }\end{array}$ & $\begin{array}{l}\text { No. of } \\
\text { patient } \\
\text { occurrence }\end{array}$ & P value \\
$\begin{array}{l}\text { Transient ocular } \\
\text { burning/ discomfort }\end{array}$ & 1 & Non-significant \\
\hline Ocular irritation & 0 & Non-significant \\
\hline Redness & 0 & Non-significant \\
\hline Stinging & 0 & Non-significant \\
\hline Pruritis & 0 & Non-significant \\
\hline Photophobia & 0 & Non-significant \\
\hline Ocular watering & 0 & Non-significant \\
\hline Dryness & 0 & Non-significant \\
\hline
\end{tabular}

Table 4: Group B: the occurrence of adverse effects with topical $0.3 \%$ ofloxacin otic solution therapy.

\begin{tabular}{|lll|}
\hline $\begin{array}{l}\text { Adverse effects of } \\
\text { 0.3\% ofloxacin otic } \\
\text { solution }\end{array}$ & $\begin{array}{l}\text { No. of } \\
\text { patient } \\
\text { occurrence }\end{array}$ & P value \\
\hline Pruritis & 1 & Non-significant \\
\hline Headache & 0 & Non-significant \\
\hline Dizziness & 0 & Non-significant \\
\hline Mild ear pain & 0 & Non-significant \\
\hline Rash & 0 & Non-significant \\
\hline $\begin{array}{l}\text { Hypersensitivity } \\
\text { reactions }\end{array}$ & 0 & Non-significant \\
\hline
\end{tabular}

Table 5: Pharmacovigilance causality assessment grading and staging scores.

\begin{tabular}{|c|c|c|c|c|}
\hline Causality assessment attributes & $\begin{array}{l}\text { Causality } \\
\text { grading for } \\
\text { ofloxacin } \mathbf{0 . 3 \%} \\
\text { ophthalmic } \\
\text { therapy }\end{array}$ & $\begin{array}{l}\text { Causality } \\
\text { grading for } \\
\text { ofloxacin } \\
\mathbf{0 . 3 \%} \text { otic } \\
\text { therapy }\end{array}$ & $\begin{array}{l}\text { Staging of } \\
\text { causality grades } \\
\text { for ofloxacin } \\
0.3 \% \text { ophthalmic } \\
\text { therapy }\end{array}$ & $\begin{array}{l}\text { Staging of } \\
\text { causality } \\
\text { grades for } \\
\text { ofloxacin } 0.3 \% \\
\text { otic therapy }\end{array}$ \\
\hline $\begin{array}{l}\text { History of hypersensitivity to the same } \\
\text { drug administered }\end{array}$ & -1 & -1 & None & None \\
\hline $\begin{array}{l}\text { History of hypersensitivity to the same } \\
\text { generic category of drug administered }\end{array}$ & -1 & -1 & None & None \\
\hline $\begin{array}{l}\text { History of adverse drug reaction-like } \\
\text { symptoms previously }\end{array}$ & -1 & -1 & None & None \\
\hline $\begin{array}{l}\text { Occurrence of adverse drug reaction } \\
\text { after the suspected drug administration }\end{array}$ & +1 & +1 & Mild & Mild \\
\hline $\begin{array}{l}\text { Improvement of adverse drug effects } \\
\text { after discontinuation of drug, } \\
\text { modification of drug dose, alternate } \\
\text { drug administration, or specific } \\
\text { antagonist administration }\end{array}$ & -1 & -1 & None & None \\
\hline $\begin{array}{l}\text { Appearance of adverse drug effects after } \\
\text { re-continuation of drug, reversal to } \\
\text { previous drug dose on patient } \\
\text { stabilization, reversal to previous drug } \\
\text { administration, or discontinuation of } \\
\text { antagonist administration }\end{array}$ & -1 & -1 & None & None \\
\hline
\end{tabular}




\begin{tabular}{|c|c|c|c|c|}
\hline Causality assessment attributes & $\begin{array}{l}\text { Causality } \\
\text { grading for } \\
\text { ofloxacin } \mathbf{0 . 3 \%} \\
\text { ophthalmic } \\
\text { therapy }\end{array}$ & $\begin{array}{l}\text { Causality } \\
\text { grading for } \\
\text { ofloxacin } \\
0.3 \% \text { otic } \\
\text { therapy }\end{array}$ & $\begin{array}{l}\text { Staging of } \\
\text { causality grades } \\
\text { for ofloxacin } \\
0.3 \% \text { ophthalmic } \\
\text { therapy }\end{array}$ & $\begin{array}{l}\text { Staging of } \\
\text { causality } \\
\text { grades for } \\
\text { ofloxacin } 0.3 \% \\
\text { otic therapy }\end{array}$ \\
\hline $\begin{array}{l}\text { Alternative co-existing sources, like } \\
\text { disease or medications, causing adverse } \\
\text { drug effect-like reaction }\end{array}$ & -1 & -1 & None & None \\
\hline $\begin{array}{l}\text { False adverse drug effect mimicking } \\
\text { reactions }\end{array}$ & -1 & -1 & None & None \\
\hline $\begin{array}{l}\text { Appearance of adverse drug effect with } \\
\text { a placebo }\end{array}$ & -1 & -1 & None & None \\
\hline $\begin{array}{l}\text { Detection of the suspected drug in body } \\
\text { fluids in toxic concentrations }\end{array}$ & -1 & -1 & None & None \\
\hline $\begin{array}{l}\text { Severity of adverse drug reactions with } \\
\text { increase or decrease of drug dose }\end{array}$ & -1 & -1 & None & None \\
\hline $\begin{array}{l}\text { Occurrence of adverse drug reactions } \\
\text { with the suspected drug in a time- } \\
\text { variant or place-variant manner }\end{array}$ & -1 & -1 & None & None \\
\hline
\end{tabular}

Causality grading: $Y e s=+1$, no=-1, uncertain $=0$, Staging of causality grades: None, mild, moderate, severe, Causality assessment scoring: $\geq 9$ severe on average $=$ Definite causality of adverse drug reaction, 5-8 moderate severe on average $=$ Probable causality of adverse drug reaction, 1-4 mild-moderate on average $=$ Possible causality of adverse drug reaction, $\leq 0$ mild or none on average $=$ Doubtful/unlikely causality of adverse drug reaction, $\leq 0->0$ variable $=$ variable on average $=$ Conditional/unclassified causality of adverse drug reaction, $\geq 0$ variable $=$ variable on average $=U$ n assessable/unclassifiable causality of adverse drug reaction .

\section{DISCUSSION}

In a study, administering $0.3 \%$ ofloxacin topically 4 times daily to the eyes of 30 normal healthy adults resulted in tear ofloxacin concentrations ranging from 1.2 to $22 \mu \mathrm{g} / \mathrm{g}$ (mean $9.2 \mu \mathrm{g} / \mathrm{g}$ ) four hours after the first dose on the eleventh day of treatment. The mean tear concentration varied between 5.7 and $31 \mu \mathrm{g} / \mathrm{g}$ during the time period between 5 and 40 minutes after instillation of the second dose on day 11 . In this same study, mean serum plateau levels of $0.97 \mathrm{ng} / \mathrm{mL}$ after $1^{\text {st }}$ dose (day 1) and $1.66 \mathrm{ng} / \mathrm{mL}$ after the $41^{\text {st }}$ dose (day 11) was achieved. The maximum serum level from multiple topical dosing $(1.9 \mathrm{ng} / \mathrm{mL})$ was approximately 2000-fold less than the maximum serum level achieved from treatment with a single $300 \mathrm{mg}$ oral dose $(4620 \mathrm{ng} / \mathrm{mL})$. Time to reach $90 \%$ of the plateau serum concentration was 0.9 hours after the initial dose on day 1 compared with 0.5 hours on day 11 , indicating a change in the rate of systemic absorption from ophthalmic dosing. Total drug recovery (urinary excretion of intact drug plus unabsorbed dose recovered from tear overflow) was $78 \%$ on day 1 and $90 \%$ on day 10 .

In systemic pharmacokinetic studies, ofloxacin was rapidly absorbed into the blood stream following oral dosing, with peak serum concentrations $\left(\mathrm{C}_{\max }\right)$ increasing in a dose related manner. There was no significant increase in peak serum ofloxacin concentration following multiple oral administrations. Cumulative urinary recovery of ofloxacin 48 hours after dosing ranged from $83 \%$ to $99 \%$ of the administered dose. This indicates that ofloxacin is mainly excreted by renal elimination. The metabolism of ofloxacin was studied in 5 healthy adult male volunteers receiving a single oral dose of a $600 \mathrm{mg}$ mixture of ofloxacin and deuterium-labelled ofloxacin. Ofloxacin and its metabolites were identified, confirmed and quantified. Urinary concentration of ofloxacin increased to a maximum of $686.6 \mu \mathrm{g} / \mathrm{ml}$ at 2-4 hours after dosing and was maintained above $273.9 \mu \mathrm{g} / \mathrm{ml} 4-24$ hours after dosing. Cumulative urinary excretion of ofloxacin was $79.5 \%$ at 48 hours after dosing. Urinary concentrations of desmethyl ofloxacin were 10.4 and $6.6 \mu \mathrm{g} / \mathrm{ml}$ at $2-4$ and $12-24$ hours after dosing, concentrations of ofloxacin N-oxide were 7.8 and $2.7 \mu \mathrm{g} / \mathrm{ml}$ at $2-4$ and $12-24$ hours after dosing. Urinary concentrations of these metabolites were less than $2.5 \%$ of the excreted concentration of ofloxacin at each time interval. The results of this study indicate that ofloxacin exists mainly as parent drug in vivo, and is excreted mainly unchanged in the urine in humans. ${ }^{2,7,10,14}$

In a study, patients were randomly assigned to receive either $0.5 \%$ levofloxacin $(n=211)$ or $0.3 \%$ ofloxacin $(n=212)$ for 5 days (every 2 hours on days 1 and 2 and every 4 hours on days 3-5). Conjunctival cultures were obtained, and ocular signs and symptoms were evaluated on day 1 (baseline), days 3 to 5 (interim), and days 6 to 10 (final). End point was defined as the last evaluable observation. Both study medications were well tolerated, with a low incidence of adverse events. Despite the higher concentration of active drug in $0.5 \%$ levofloxacin versus $0.3 \%$ ofloxacin, there was no difference between treatment groups in the incidence of treatment-related adverse events. $^{15}$

In two single-dose studies, mean ofloxacin serum concentrations were low in adult patients with tympanostomy tubes, with and without otorrhoea, after otic administration of a $0.3 \%$ solution $[4.1 \mathrm{ng} / \mathrm{ml}(\mathrm{n}=3)$ and $5.4 \mathrm{ng} / \mathrm{ml}(\mathrm{n}=5)]$, respectively. In adults with perforated tympanic membranes, the maximum serum drug level of 
the middle ear mucosa of some adult subjects, with perforated tympanic membranes (11 of 16 subjects). The variability of ofloxacin concentration in middle ear mucosa was high. The concentrations ranged from 1.2 $\mathrm{mcg} / \mathrm{g}$ to $602 \mathrm{mcg} / \mathrm{g}$, after otic administration of $3 \%$ solution. , $^{2,10,16}$

In another study, in 38 patients, in the age range of 3-81 years, for measuring the concentration of ofloxacin in otorrhoea, serum and middle ear mucosa, after the topical administration of $0.3 \%$ ofloxacin otic solution, administered in a single dose of $0.5 \mathrm{ml}$ in adults, $0.25 \mathrm{ml}$ in children with chronic suppurative otitis media and perforated tympanic membrane, with serial sampling of otorrhoea and serum up to 8 hours after dosing and middle ear mucosa up to 2 hours after dosing, it was observed that high concentrations of ofloxacin were measured in otorrhoea samples taken immediately after dosing, followed by a rapid nonlogarithmic decline. Elimination of the drug through otorrhoea was believed to be related to loss from the application site with ear drainage rather than to biologic mechanisms. Maximum concentration of ofloxacin in otorrhoea was seen at the initial sampling time, 30 minutes after dosing, with concentrations measured up to the last sampling at 8 hours. Very low concentrations of ofloxacin were found in serum after topical administration of the drug. Concentrations were not detected in serum samples of most of the patients. The highest concentration measured was $10 \mathrm{ng} / \mathrm{ml}$. Drug concentrations were detected primarily in samples obtained up to 1 hour after the dose was administered. Mucosal drug concentrations were highly variable, ranging from non-detectable to $602 \mu \mathrm{g} / \mathrm{g}$. No adverse events were observed. No clinically significant adverse changes in laboratory test results or audiometric result were observed. Thus, drug concentrations were high in otorrhoea, very low or not detected in serum and highly variable in middle ear mucosa. Non-biologic loss of the drug with the ear drainage through the external auditory canal and the eustachian tube was probably related to the high concentration in otorrhoea samples. Drug concentration in middle ear mucosa suggest that the drug reaches the infection site. ${ }^{17}$

In this study, safety assessment in group A and group B patients demonstrated that the occurrence of adverse effects was statistically non-significant. In group A, the causality grading was 'yes' $=+1$ for 1 attribute: occurrence of adverse drug reaction after the suspected drug administration, and 'no'=-1 for other attributes, with causality Staging of 'mild' for 1 causality assessment attribute, and 'none', for other attributes, because there was occurrence of transient ocular discomfort in only 1 patient, the first day, which reduced within 24 hours, on drug adaptation with time. In group $B$, the causality grading was 'yes' $=+1$ for 1 attribute: occurrence of adverse drug reaction after the suspected drug administration, and 'no'=-1 for other attributes, with causality staging of 'mild' for 1 attribute, and 'none', for other attributes, because there was occurrence of mild pruritis in only 1 patient, the first day, which also reduced within 24 hours, on drug adaptation with time. The causality assessment scoring for each ofloxacin $0.3 \%$ ophthalmic therapy and $0.3 \%$ otic therapy was: -11 , none on average=unlikely causality of adverse drug reaction, because the occurrence of adverse effects in group A and group B was statistically non-significant. The patients' adherence to ofloxacin treatment was very high.

\section{CONCLUSIONS}

Both topical ofloxacin $0.3 \%$ ophthalmic and otic solutions, were safe and tolerable in the patients, with statistically non-significant causality of association.

\section{ACKNOWLEDGEMENTS}

Author would like to thanks to Dr. Moumita Hazra's polyclinic and diagnostic centre, Hazra nursing home, J. J. M. medical college and hospitals, Rama medical college hospital and research centre and Rama university, Mamata medical college and hospitals, and Shri Ramkrishna institute of medical sciences and Sanaka hospitals, for the successful completion of this research project.

Funding: No funding sources

Conflict of interest: None declared

Ethical approval: The study was approved by the Institutional Ethics Committee

\section{REFERENCES}

1. Bryskier A. Fluoroquinolones. In: Bryskier A ed. Antimicrobial agents: Antibacterials and antifungals. $1^{\text {st }}$ ed. USA: ASM Press. 2005;668-788.

2. Mohammed HHH, Abuo-Rahma GEAA, Abbas SH, Abdelhafez EMN. Current trends and future directions of fluoroquinolones. Curr Med Chem. 2019;26(17):3132-49.

3. Hazra M. A multivariate comparative clinical pharmacotherapeutic efficacy and chronopharmacovigilance assessment study of ofloxacin, one of the commonplace TGF $\beta 1$ inducing and telomerase impairing fluoroquinolones, in treating acute gastroenteritis, chronic obstructive pulmonary disease, new drug-sensitive tuberculosis, recurrent mixed cutaneous infections, and postsurgical refractory wound infections, among the global patients, with heterogenous pharmacogeographic and pharmacogenomic constitution. Int J Basic Clin Pharmacol. 2021;10(3):270-80.

4. Karampela I, Dalamaga M. Could respiratory fluoroquinolones, levofloxacin and moxifloxacin, prove to be beneficial as an adjunct treatment in COVID-19? Arch Med Res. 2020;51(7):741-2.

5. Brar RK, Jyoti U, Patil RK, Patil HC. Fluoroquinolone antibiotics: an overview. Adesh Univ J Med Sci Res. 2020;2(1):26-30. 
6. Tripathi KD. Sulfonamides, Cotrimoxazole and Quinolones. In: Tripathi M, ed. Essentials of Medical Pharmacology. $7^{\text {th }}$ ed. New Delhi, London, Philadelphia, Panama: Jaypee Brothers Medical Publishers Ltd. 2013;708-715.

7. MacDougall C. Sulfonamides, TrimethoprimSulfamethoxazole, Quinolones, and Agents for Urinary Tract Infections. In: Brunton LB, HilalDandan R, Knollmann BC, eds. Goodman and Gilman's The Pharmacological Basis of Therapeutics. $13^{\text {th }}$ ed. New York, Chicago, San Francisco, Athens, London, Madrid, Mexico City, Milan, New Delhi, Singapore, Sydney, Toronto: McGraw-Hill. 2018;1067-86.

8. Yadav V, Talwar P. Repositioning of fluoroquinolones from antibiotic to anti-cancer agents: an underestimated truth. Biomed Pharmacother. 2019;111:934-46.

9. World Health Organization. 2020. Differences among fluoroquinolones in the treatment of MDR-TB. World Health Organisation Archives. Available at: https://www.archives.who.int. Accessed on 10 January 2021.

10. Azad HK, Assar S, Nosratabadi. A review of immunomodulatory effects of fluoroquinolones. Immunol Invest. 2020;1-20.

11. Karampela I, Dalamaga M. Could respiratory fluoroquinolones, levofloxacin and moxifloxacin, prove to be beneficial as an adjunct treatment in COVID-19? Arch Med Res. 2020;51(7):741-2.

12. Naranjo CA, Busto U, Sellers EM, Sandor P, Ruiz I, Roberts EA et al. A method for estimating the probability of adverse drug reactions. Clin Pharmacol Ther. 1981;30(2):239-45.

13. WHO-UMC System for standardized case causality assessment. World Health Organisation (WHO)Uppsala Monitoring Centre, 2013. Available at: http://www.who-umc.org/Graphics/24734.pdf. Accessed 30 November 2021.

14. The United States Food and Drug Administration. Product monograph: Ofloxacin ophthalmic solution $0.3 \%$ antibacterial agent, 2016. Available at: https://www.accessdata.fda.gov/drugsatfda_docs/lab el/2016/019921s021lbl.pdf. Accessed 5 December 2021.

15. Schwab IR, Friedlaender M, McCulley J, Lichtenstein SJ, Moran CT. A phase III clinical trial of $0.5 \%$ levofloxacin ophthalmic solution versus $0.3 \%$ ofloxacin ophthalmic solution for the treatment of bacterial conjunctivitis. Ophthalmology. 2003;110(3):457-65.

16. Drugs.com. Ofloxacin ear drops, 2020. Available at: https://www.drugs.com/mtm/ofloxacin-otic.html. Accessed 5 December 2021.

17. Ohyama M, Furut S, Ueno K, Katsuda K, Nabori T, Kiyota R et al. Ofloxacin otic solution in patients with otitis media: An analysis of drug concentrations. Arch Otolaryngol Head Neck Surg. 1999;125:337-40.

Cite this article as: Hazra M. A comparative study on the pharmacovigilance scoring of causality assessment grading and staging of topical pharmacotherapy of ofloxacin $0.3 \%$ ophthalmic solution in bacterial conjunctivitis and ofloxacin $0.3 \%$ otic solution in otitis externa. Int $\mathrm{J}$ Basic Clin Pharmacol 2022;11:173-80. 